\title{
Modafinil decreases anxiety-like behaviour in zebrafish
}

\author{
Adrian Johnson ${ }^{1}$, Trevor James Hamilton ${ }^{\text {Corresp. } 1,2}$ \\ 1 Psychology, MacEwan University, Edmonton, Alberta, Canada \\ 2 Neuroscience and Mental Health Institute, Universtiy of Alberta, Edmonton, Canada \\ Corresponding Author: Trevor James Hamilton \\ Email address: trevorjameshamilton@gmail.com
}

Modafinil (2-((diphenylmethyl)sulfinyl)acetamide), a selective dopamine and norepinephrine transporter inhibitor, is most commonly prescribed for narcolepsy but has gained recent interest for treating a variety of disorders. Zebrafish (Danio rerio) are becoming a model of choice for pharmacological and behavioural research. To investigate the behavioural effects of modafinil on anxiety, we administered doses of $0,2,20$, and 200 $\mathrm{mg} / \mathrm{L}$ for 30 minutes then tested zebrafish in the novel approach test. In this test the fish was placed into a circular arena with a novel object in the center and motion-tracking software was used to quantify the time the fish spent in the outer area of the arena (thigmotaxis zone), middle third of the arena (transition zone) and center of the arena, as well as total distance traveled, immobility and meandering. Modafinil caused a decrease in time spent in the thigmotaxis zone and increased time spent in the transition zone across all doses. Modafinil did not significantly alter the time spent in the center zone (near the novel object), the distance moved, meandering, or the duration of time spent immobile. We also validated this test as a measure of anxiety with the administration of ethanol (1\%) which decreased time spent in the thigmotaxis zone and increased time spent in the transition zone. These results suggest that modafinil decreases anxiety-like behaviour in zebrafish. 
1 Modafinil decreases anxiety-like behaviour in zebrafish

3 Adrian Johnson ${ }^{1}$, Trevor James Hamilton ${ }^{1,2 *}$,

$5 \quad{ }^{1}$ Department of Psychology, MacEwan University, Edmonton, AB, Canada, T5J 4S2.

62 Neuroscience and Mental Health Institute, University of Alberta, Edmonton, AB, Canada, T6G $7 \quad 2 \mathrm{H} 7$.

*Corresponding author: trevorjameshamilton@gmail.com, phone: 1-780-633-3584

\section{Abstract}

12 Modafinil (2-((diphenylmethyl)sulfinyl)acetamide), a selective dopamine and norepinephrine transporter inhibitor, is most commonly prescribed for narcolepsy but has gained recent interest

14 for treating a variety of disorders. Zebrafish (Danio rerio) are becoming a model of choice for pharmacological and behavioural research. To investigate the behavioural effects of modafinil on anxiety, we administered doses of $0,2,20$, and $200 \mathrm{mg} / \mathrm{L}$ for 30 minutes then tested zebrafish in the novel approach test. In this test the fish was placed into a circular arena with a novel object in the center and motion-tracking software was used to quantify the time the fish spent in

19 the outer area of the arena (thigmotaxis zone), middle third of the arena (transition zone) and center of the arena, as well as total distance traveled, immobility and meandering. Modafinil

21 caused a decrease in time spent in the thigmotaxis zone and increased time spent in the transition 
22 zone across all doses. Modafinil did not significantly alter the time spent in the center zone (near

23 the novel object), the distance moved, meandering, or the duration of time spent immobile. We

24 also validated this test as a measure of anxiety with the administration of ethanol (1\%) which

25 decreased time spent in the thigmotaxis zone and increased time spent in the transition zone.

26 These results suggest that modafinil decreases anxiety-like behaviour in zebrafish. 


\section{Introduction}

Modafinil (2-((diphenylmethyl)sulfinyl)acetamide) (brand name Alertec in Canada, Provigil in the United States, and Modavigil in Australia) is a psychostimulant primarily used by narcolepsy patients and shift workers to alleviate sleep related disorders. It is being tested as a potential treatment for major depressive disorder (MDD), cocaine-addiction, and as a cognitive enhancer (Abolfazli, et al., 2011; Dean, et al., 2011; Minzenberg \& Carter, 2008). Modafinil is thought to inhibit dopamine transporters (Madras et al., 2006; Volkow et al., 2009) as well as and norepinephrine transporters (Madras et al., 2006) leading to increased synaptic dopamine and norepinephrine, respectively, but not to a level stimulating abuse of the drug. It is shown to reduce GABA (y-aminobutyric acid) levels, and increase levels of serotonin (5HT), glutamate, orexin, and histamines in the brain (Minzenberg \& Carter, 2008, Mereu et al., 2013). Because of its action on these neurotransmitter systems and low abuse profile, modafinil has the potential for a wide therapeutic benefit.

Modafinil has a variety of effects on anxiety in humans and anxiety-like behaviour in animal models. Some studies have shown anxiety generating (anxiogenic) effects in humans, while others show anxiety reducing (anxiolytic) effects. In an emotion and cognition test, Rasetti, et al. (2010) found that 7 days of modafinil (100 mg/day) increased the efficacy of prefrontal cognitive information processing in humans, while reducing the reactivity to fearful and threatening stimuli through the amygdala (controlling anxiety). However, in other studies, repeated doses of modafinil given to sleep apnea patients (200-400 mg/day, 4 weeks; Schwartz, Hirshkowitz, \& Erman, 2003), and narcoleptic patients (400 mg/day, 2 weeks; Broughton, et al., 1997) caused an increase in nervousness and/or anxiety. In another study, Randall, Shneerson, 
Plaha, \& File (2003) found that doses of 100-800 mg in 'healthy young volunteers' had significant anxiogenic effects. Therefore, it is still inconclusive as to what type of anxietyaltering response modafinil might produce in humans.

Often we can move to animal models to find answers to pharmacological questions, however, animal models have also shown differing effects of modafinil. In rhesus macaque monkeys (Macaca mulatta), single doses of modafinil have been shown to increase nocturnal activity but did not decrease anxiety responses (Hermant, et al., 1991). Van Vliet, Jongsma, Vanwersch, Olivier, \& Philippens (2006) found an anxiolytic response in marmoset monkeys (Callithrix jacchus) when recording their startle responses to a threat situation after a single oral dose of modafinil (between 50-225 mg/kg). In male swiss albino mice (Mus musculus), Simon, Panissaud \& Costentin (1994) compared modafinil to dexamphetamine (another known stimulant) and measured the relative stimulant properties as well as anxiety levels generated by these substances. Of the three tests used (black and white compartment test, elevated plus maze, and open field task), modafinil did not increase any anxiety behaviours. Interestingly, modafinil dose-dependently increases spontaneous exploration in C57BL/6J mice (Young et al., 2011). These studies in animal models also demonstrate an inconsistent effect of modafinil on anxiety and exploratory behaviour.

Zebrafish (Danio rerio), have become a popular animal model used in the scientific community due to their fecundity, larval-stage transparency, short gestational period, and ease in handling (Gerlai, 2010; Stewart et al., 2014). The similarity in zebrafish genetic and behavioural markers to those in humans make this species-an ideal model organism for studying pharmacological compounds (Spence et al., 2008; Tierney 2011). To date only one study examined the effect of modafinil on zebrafish behaviour and it was performed on larval zebrafish 
73 (6 days post-fertilization). Sigurgeirsson et al., (2011) found that modafinil causes a dose-

74 dependent reduction in sleep. Specifically, they found that modafinil had no effect on the number of transitions between sleep and wakefulness throughout a 24 hour monitoring period, but had a decrease in the mean sleep percentages of fish as the dosages increased, especially in the 12 hours in which the lights were off at night. Modafinil increased the wakeful bouts of fish whilst maintaining the structure of sleep, however these researchers did not perform any cognitive or anxiety-related behavioural tests. To date, the effects of modafinil in larval or adult zebrafish remains relativity unexplored.

In this study we used the novel approach test, a test of anxiety in zebrafish (Stewart et al., 2012) and other fish species (Ou et al., 2015). In this test the fish is placed into a circular arena with a novel object in the center. Typically, zebrafish are fearful of the novel object (neophobic) and spend time near the wall of the arena (thigmotaxis). With a camera-based motion-tracking software system we quantified the time near the object, near the wall, and in a transition zone in the middle, as well as distance moved, meandering, and immobility, after a 30 minute exposure to modafinil $(2,20$, and $200 \mathrm{mg} / \mathrm{L})$ or ethanol $(1 \%)$.

\section{Materials and Methods}

The experimental procedures were approved by the MacEwan University Animal Research Ethics Board (AREB; protocol number 05-12-13). These standards are in compliance with the Canadian Council for Animal Care (CCAC).

\section{Subjects}

This study used 138 adult wild-type zebrafish (Danio rerio) that were held in a 3-shelf benchtop housing system (Aquatic Habitats) in either 3 or 10 L polypropylene tanks. The fish 
95

96

97

98

99

100

101

102

103

104

105

106

107

108

109

110

111

112

113

114

115

116

117

were obtained from Aquatic Imports (Calgary, AB) and the gender was unidentified. Habitat water was made in the lab by purifying tap water through reverse osmosis (RO), then adding 5 $\mathrm{mL}$ of prime (sodium thiosulphate), $25 \mathrm{~g}$ of aquarium salt, $10-18 \mathrm{~g}$ of $\mathrm{NaHCO}_{3}$, and $100 \mathrm{~mL}$ of acetic acid were added for every $60 \mathrm{~L}$ of RO water (Holcombe et al., 2013). The water in the habitat was continuously recirculated, treated with activated carbon, and was UV irradiated and filtered. The zebrafish were fed once daily on an alternating diet of either flake food (Gammamicro 300, New Life Products) or shrimp (Omega One Freeze Dried Shrimp Nutri-Treat, Omega

Sea Ltd.). Fish were kept on a daily 12-hour light/dark cycle with lights turning on at 8AM and off at 8PM. The water conditions in the habitat were monitored daily with the temperature maintained between $26.0^{\circ} \mathrm{C}$ and $29.0^{\circ} \mathrm{C}$, the $\mathrm{pH}$ between 7.0 and 8.0, and the dissolved $\mathrm{O}_{2}$ levels between 5.0 and $10.0 \mathrm{ppm}$.

\section{Drug Administration}

Modafinil (Toronto Research Chemicals) was administered to the fish at three different doses; 2 ( $n=19), 20(n=24)$, or $200(n=22) \mathrm{mg} / \mathrm{L}$. Modafinil was first dissolved in dimethyl sulfoxide (DMSO, Sigma Aldrich, St. Louis, MO) to increase solubility and this stock solution was frozen until the experimental day. This stock solution was used within 14 days of preparation and mixed with $250 \mathrm{~mL}$ of habitat water to achieve the desired dose of modafinil (the maximum amount of DMSO was $0.1 \%)$. The control group $(n=35)$ underwent otherwise identical experimental procedures (including 0.1\% DMSO) without the presence of modafinil. DMSO does not alter locomotion or anxiety-like behaviour in zebrafish (0.05\%: Sackerman et al., 2010; 0.1\%: Stewart \& Kaleuff, 2014; 0.1\% Kolesnikova et al., 2016) so a separate control group was not included in this part of the study. Zebrafish were individually administered modafinil or control solutions for 30 minutes in $600 \mathrm{ml}$ containers before testing began. Each drug group was 
118 performed on two days of testing, with controls interspersed throughout the day at a 2:1

119 (drug:control) ratio, resulting in $\sim \mathrm{n}=20$ for each drug group and $n=35$ for the controls. The drug

120

121

122

123

solution was made fresh each day and maintained at $26-28^{\circ} \mathrm{C}$. All of the fish used in this experiment were experimentally and drug naïve. Doses were based on previous studies using modafinil (Sigurgeirsson et al., 2011) and other similar psychostimulants (Sackerman et al., 2010) in adult zebrafish.

Ethanol is commonly used as an anxiolytic drug in zebrafish studies (Holcombe et al., 2014; Tran et al., 2016; Tran et al., 2016b) so we used this to validate the novel approach test as a measure of anxiety in a second experiment. Ethanol (non-denatured) was added to habitat water in the same $600 \mathrm{ml}$ containers used for modafinil to reach a final concentration of $1 \%$ (volume/volume percentage). Zebrafish were individually placed in the solutions for 30 minutes prior to testing. These experiments were performed on two successive days of testing, with controls interspersed throughout the day at a 1:1 (ethanol:control) ratio, resulting in $n=20$ for the ethanol group and $n=19$ for the controls.

\section{Behavioural Testing}

Testing was performed during the light hours of 12-hour light/dark cycle. On the day of testing, the fish were transported in their housing tank to the experimental area. The fish were individually placed in either the control or modafinil solution $(2,20$, or $200 \mathrm{mg} / \mathrm{L})$ for 30 minutes. Following drug administration the fish were placed in the circular arena placed into the novel approach test arena; a circular white plastic arena with at diameter of $34 \mathrm{~cm}$ and walls that were $16 \mathrm{~cm}$ high (Figure 1A). The arena was filled with $6 \mathrm{~cm}$ of habitat water that was maintained at $26-28^{\circ} \mathrm{C}$ using a heat mat (Seedling Heat Map - HydroFarm) placed underneath the arena. Water was changed after every 4 fish. A Lego figurine was placed in the middle of the 
141 arena during testing and was used as the novel object in this paradigm (Figure 1B) similar to 142 other studies (Ou et al., 2015). It was held in place with a $1.5 \mathrm{~cm}$ x $1.5 \mathrm{~cm}$ square of Velcro glued

143 to the feet of the Lego figurine and the arena floor. The height of the water completely

144 submerged the figurine. The fish were placed into the arena and recorded for 10 minutes.

145

146

147

148

149

150

151

152

153

154

155

156

157

158

159

160

161

162

163

Dependent variables were measured using EthoVision XT (version 10; Noldus) motion tracking

software. In EthoVision, the arena was divided into three zones, the center, transition, and

thigmotaxis zone. The center zone consisted of a $10 \mathrm{~cm}$ diameter circle with the middle on top of

the object. The thigmotaxis zone was a circular zone from the wall $4.5 \mathrm{~cm}$ (one body length of a zebrafish) toward the center of the arena. The transition zone was the zone in between the center zone and thigmotaxis zone. The variables measured were time in each zone (center, transition, thigmotaxis), distance moved, meandering (the change in direction of movement relative to the distance moved), and duration immobile. To calculate meandering we filtered the trials with the 'minimal distance method' in EthoVision. This eliminates the inclusion of directionality when the fish is still or only minimally moving. Following the behavioural testing the fish were placed back into their housing tanks.

\section{Statistical Analysis}

A D’Agostino \& Pearson omnibus normality test was used to assess normality for all data sets. One-way ANOVA with a post hoc Dunn's Multiple Comparison Test or unpaired t-test was used with parametric data and nonparametic data was analyzed with a Kruskal-Wallis or MannWhitney test. Absolute time in each zone was measured as duration (s) in zones for the full 10 minute trial. Meandering was quantified using the 'absolute meandering' option in EthoVision. This calculates that total change in angle that the fish moves over the trial in degrees per centimeter. Immobility was defined in as the percent change in the pixels of the fish from frame 
164 to frame and was set at a threshold of 5\% (Pham et al., 2009). The behavioural data was analyzed

165

166 using GraphPad Prism software (version 6). Data are shown as mean \pm s.e.m.

\section{Results}

Zebrafish were exposed to doses of 0 (control), 2, 20, and $200 \mathrm{mg} / \mathrm{L}$ for 30 minutes then immediately tested zebrafish in the novel approach test. Figure 2 is a representative example of the movement of one zebrafish over the duration of the 10 minute trial under control conditions (Figure 2A) and another zebrafish after being exposed to $200 \mathrm{mg} / \mathrm{L}$ of modafinil (Figure 2B). The heatmaps are examples of the same responses but with pseudocolour representation of the location of the fish over time (Figures 2C-D).

\section{Modafinil: Time in zones}

To examine the effects of modafinil on anxiety and exploratory behaviour using the novel approach test, the time spent in the center, transition, and thigmotaxis zones were measured. We found that time spent in the thigmotaxis zone was significantly decreased for all modafinil groups compared to control (Figure 3A; control: $494.2 \pm 9.8 \mathrm{~s}, 2 \mathrm{mg} / \mathrm{L}: 449.3 \pm 15.8 \mathrm{~s}, 20 \mathrm{mg} / \mathrm{L}$ : $441.4 \pm 12.5 \mathrm{~s}, 200 \mathrm{mg} / \mathrm{L}: 448.1 \pm 16.5 \mathrm{~s} ; \mathrm{F}(3,96)=4.168, \mathrm{P}=0.008)$. Time spent in the transition zone was significantly greater for all groups compared to controls (Figure 3B, control: $101.5 \pm 9.3 \mathrm{~s}, 2 \mathrm{mg} / \mathrm{L}: 144.9 \pm 14.7$ s, $20 \mathrm{mg} / \mathrm{L}: 149.9 \pm 11.9$ s, $200 \mathrm{mg} / \mathrm{L}: 144.4 \pm 15.1 \mathrm{~s} ; \mathrm{F}$ $(3,96)=4.136, \mathrm{P}=0.008)$. There was no significant difference in time spent in the center zone across all groups (Figure 3C; control: $4.3 \pm 0.9 \mathrm{~s}, 2 \mathrm{mg} / \mathrm{L}: 5.8 \pm 1.5 \mathrm{~s}, 20 \mathrm{mg} / \mathrm{L}: 8.7 \pm 2.5 \mathrm{~s}, 200$ $\mathrm{mg} / \mathrm{L}: 7.5 \pm 1.7 \mathrm{~s} ; \mathrm{H}(3)=5.727, \mathrm{P}=0.1257)$.

\section{Modafinil: Locomotion}


186 distance moved, meandering, and duration the fish was immobile. The drug treatment groups did not significantly differ from the control group in the distance moved (Figure 4A; control $5537 \pm$ $164 \mathrm{~cm}, 2 \mathrm{mg} / \mathrm{L}: 5957 \pm 328 \mathrm{~cm}, 20 \mathrm{mg} / \mathrm{L}: 5410 \pm 266 \mathrm{~cm}, 200 \mathrm{mg} / \mathrm{L}: 5288 \pm 209 \mathrm{~cm}, \mathrm{~F}(3,96)=$ $1.277, \mathrm{p}=0.2868$ ). No significant difference was found for meandering (Figure 4B; control: 7.9 $\pm 1.6 \% \mathrm{~cm}, 2 \mathrm{mg} / \mathrm{L}: 7.9 \pm 1.5 \% \mathrm{~cm}, 20 \mathrm{mg} / \mathrm{L}: 6.3 \pm 0.7 \% \mathrm{~cm}, 200 \mathrm{mg} / \mathrm{L}: 6.9 \pm 1.2 \% \mathrm{~cm}, \mathrm{H}(3)=$ $0.6190, \mathrm{P}=0.8921$ ) across all groups. There was no significant difference in immobility (Figure 4C: control: $4.9 \pm 1.6 \mathrm{~s}, 2 \mathrm{mg} / \mathrm{L}: 3.8 \pm 2.2 \mathrm{~s}, 20 \mathrm{mg} / \mathrm{L}: 11.8 \pm 5.2 \mathrm{~s}, 200 \mathrm{mg} / \mathrm{L}: 17.3 \pm 7.9 \mathrm{~s}, \mathrm{H}$ (3) $=4.032, \mathrm{P}=0.2580)$ across all groups.

\section{Ethanol:Time in Zones}

In a separate set of experiments we tested whether ethanol (1\%) would also alter the location preference of zebrafish. The time spent in the center, transition, and thigmotaxis zones were measured. We found that time spent in the thigmotaxis zone was significantly decreased for the ethanol exposed fish compared to controls (Table 1). We also found that the time in the transition zone was increased for the ethanol dosed fish compared to controls (Table 1). There was no significant difference in time spent in the center zone between ethanol exposed fish and controls (Table 1).

\section{Ethanol: Locomotion}

Ethanol did not have a significant affect on distance moved or meandering (Table 1). However, ethanol did significantly increase the time the fish spent immobile (Table 1).

\section{Discussion}


Our findings show that the acute administration of modafinil decreases anxiety-like behaviour in zebrafish across a range of doses. In particular, zebrafish administered 2, 20, and $200 \mathrm{mg} / \mathrm{L}$ modafinil spent significantly less time in the thigmotaxic zone near the walls of the arena, and more time in the transition zone of the novel approach test (Figures 2 and 3). Ethanol (1\%) also increased time spent in the transition zone and decreased time spent in the thigmotaxis zone. This type of behaviour is consistent with decreased anxiety, and has been observed in zebrafish with anxiolytic compounds resulting in less time near the walls of an open field test (Maximino et al., 2010). We observed no significant modafinil-induced changes in locomotion; distance moved, meandering, and immobility, therefore, their zone preference was not due to a locomotor alteration. These results suggest that modafinil decreases anxiety in zebrafish.

The novel approach test involves placing a fish into a circular arena containing a novel object in the center. The innate fear response for a never-before seen object (neophobia) is the behaviour of interest in zebrafish, as they have a tendency to remain away from the object that they may perceive as a predator (Wright et al., 2006, Moretz et al., 2007). This has been pharmacologically validated in juvenile pink salmon with the $\mathrm{GABA}_{\mathrm{A}}$ receptor antagonist, gabazine, an anxiogenic compound that decreased time near the novel object and increased time in the thigmotaxis zone (Ou et al., 2015). In this study we also validated the novel approach test as a measure of anxiety with the use of ethanol at a dose that has reliably decreased anxiety in other zebrafish studies (Tran et al., 2016; Tran et al., 2016b). We found that fish dosed with ethanol spent less time in the thigmotaxis zone, opposite of the anxiogenic gabazine (Ou et al., 2015). Interestingly, we found no difference in the time spent in the center zone with ethanol, suggesting that the exploration or boldness of the fish was not directly increased. Furthermore, in the present study all doses of modafinil decreased time in the thigmotaxis zone, suggesting 
230 that anxiety is reduced across all doses. There was a trend towards a decrease in distance moved 231 suggesting a potential dose-dependent effect of modafinil on activity, however this did not reach 232 significance. These findings are inconsistent with a modafinil-induced increase in rearing and 233 holepoking in mice, which can be considered 'exploration', and somewhat in contrast with the 234 elevated hyperactivity observed in mice (Young et al., 2011).

Modafinil has been shown to occupy bindings sites on the dopamine transporter (DAT) and norepinephrine transporter (NAT) with modest affinity compared to other psychostimulants like methylphenidate (Ritalin; Madras et al., 2006; Minzenberg and Carter, 2008). This action on the catecholamine system has been shown to increase extracellular dopamine in the medial prefrontal cortex of rats (de Saint Hilaire et al., 2001), striatum of mice (Wisor et al., 2001) and nucleus accumbens of rats (Ferraro et al., 1997; Munillo-Rodriuquez et al., 2007). In a recent study on the effects of modafinil on dopamine receptor knockout mice the exploratory effect of modafinil was attenuated in $\operatorname{Drdl}$ and $\operatorname{Drd} 4$ knockout mice, supporting the role of the dopamine D1 and D4 receptors in the increased exploratory response to elevated synaptic dopamine caused by modafinil (Young et al., 2011). Extracellular norepinephrine has also been shown to be increased in the prefrontal cortex and hypothalamus and extracellular serotonin increased in the prefrontal cortex and hypothalamus (de Saint Hilaire et al., 2001) frontal cortex and amygdala (Ferraro et al., 2000, 2002) of rats. In the current study we did not perform intracranial microdialysis or use receptor knockouts, however, it is likely that elevated extracellular dopamine, norepinephrine, and serotonin are also at least in part responsible for the anxiolytic effects seen in zebrafish. In other zebrafish research there is ample evidence that modulation of monoamine neurotransmission leads to changes in exploratory behaviour and anxiety. Using the norepinephrine reuptake inhibitor, desipramine $(25 \mathrm{mg} / \mathrm{L})$, and the serotonin reuptake inhibitor, 
253

254

255

256

257

258

259

260

261

262

263

264

265

266

267

268

269

270

271

272

273

274

275

citalopram (100 mg/L), Sackerman et al., (2010) demonstrated that each of these compounds increased time spent in the upper region of a novel tank diving test which is indicative of decreased anxiety. Also using the novel tank diving test, Bencan and colleagues (2009) found that buspirone $(6.25-50 \mathrm{mg} / \mathrm{L})$ which is mainly a serotonin 1A agonist (with low affinity to the dopamine D2 receptor agonist where it acts as an antagonist, and weak affinity to serotonin 2 receptor) (Loane \& Politis, 2012) also had an anxiolytic effect. Chronic administration of fluoxetine (100 $\mu \mathrm{g} / \mathrm{L}$ for 2 weeks), a selective serotonin reuptake inhibitor also produced a significant increase in time spent in the top of a novel tank diving test, decreasing anxiety. Future research with specific drugs that decrease dopamine signalling, or genetic knockouts in zebrafish, like the per $1 b$ which expresses low levels of dopamine (Huang et al., 2015) would be beneficial to further understand the mechanism of action of modafinil.

The novel approach test has been considered an appropriate test to assess anxiety in zebrafish (Wright et al., 2006, Stewart et al., 2012), although, to the best of our knowledge, has never been used with pharmacological compounds in zebrafish (Maximino et al., 2010). This research supports the novel approach test as a legitimate test for anxiety and exploratory behaviour in zebrafish and could be used with a variety of compounds. The present findings suggest that modafinil has anxiolytic properties due to the decrease in time the fish spent in the thigmotaxis zone and the increase in time the fish spent in the transition zone. Future research should test the potential nootropic properties of modafinil on zebrafish using learning paradigms like the novel object recognition test (May et al., 2015), episodic-like memory test (Hamilton et al., 2016), food-based reinforcement tasks (Ingraham et al., 2016), or other appetitive conditioning, associative learning or aversive conditioning learning and memory tests (see Gerlai, 2016 for review). If successful at enhancing memory formation or storage, modafinil 
276 could then be administered with a putative model of Alzheimer's disease, the prion protein

277 knockout model (Fleisch et al., 2013), in an attempt to rescue these deficits. Once the complex

278 drug profile of modafinil is understood, clinicians may be able to adequately prescribe it to a

279 wide range of patients. 


\section{Figure Legends}

Figure 1. Apparatus used in the novel approach test. (A) The arena used was a plastic circular arena (diameter: $34 \mathrm{~cm}$, wall height: $16 \mathrm{~cm}$ ) placed on a seeding mat to maintain water temperature. (B) The novel object was a multicolour Lego figurine (height: $5 \mathrm{~cm}$, width: $1.5 \mathrm{~cm}$ ).

Figure 2. Individual fish movement in the novel approach test. (A) Trackplot of an individual fish in the control condition for the 10 minute trial. (B) Trackplot of an individual fish in the 200 mg/L modafinil condition. (C) Heatmap of the same fish from the control condition in (A). A heatmap is a visualization of the location of the fish over the entire 10 minute trial produced in EthoVision. The colours represent the duration of time the fish spent in each pixel with low wavelengths (ex. Red) indicating high time spent and high wavelengths (ex. Blue) indicating low time spent in each pixel. (D) Heatmap for the same fish from the modafinil $200 \mathrm{mg} / \mathrm{L}$ condition in $(\mathrm{B})$.

Figure 3. Time in zones of the novel approach test. (A) The time spent in the thigmotaxis zone (near walls) of the arena decreased with modafinil. (B) The time spent in the transition zone (middle zone) of the arena increased with modafinil. (C) The time spent in the center zone (where the object was located) was not significantly different across groups. ${ }^{*} p<.05, * * p<$ 0.01, difference from control group.

Figure 4. Locomotion variables in the novel approach test. (A) There was no significant difference in distance moved across all groups. (B) There was no significant difference in meandering across all groups. (C) There was no significant difference in immobility across all groups. 


\section{Acknowledgements}

305

306

307

308

We would like to thank Melike Schalomon, Taylor Pitman, Anne Walley, Erica Loh and Aleah McCory (Animal Care Technician) for their assistance with fish husbandry. We are very grateful to Dr. Gregory de Pascale for his helpful comments on this manuscript and to Melissa Bryant for helping with the conception of this study.

\section{References}

Abolfazli, R., Hosseini, M., Ghanizadeh, A., Ghaleiha, A., Tabrizi, M., Raznahan, M., \& Akhondzadeh, S. (2011). Double-blind randomized parallel-group clinical trial of efficacy of the combination fluoxetine plus modafinil versus fluoxetine plus placebo in the treatment of major depression. Depression and Anxiety, 28(4), 297-302. doi:10.1002/da.20801.

Bencan, Z., Sledge, D., \& Levin, E. D. (2009). Buspirone, chlordiazepoxide and diazepam effects in a zebrafish model of anxiety. Pharmacology, Biochemistry and Behaviour, 94, 75-80. doi: 10.1016/j.pbb.2009.07.009

Broughton, R. J., Fleming, J. A. E., George, C.F. P., Hill, J. D., Kryger, M. H., Moldofsky, H., Montplaisir, J. Y., Morehouse, R. L., Moscovitch, A., \& Murphy, W. F. (1997). Randomized, double-blind, placebo-controlled crossover trial of modafinil in the treatment of excessive daytime sleepiness in narcolepsy. Neurology, 49(2), 444-451. doi:10.1212/WNL.49.2.444

Dean, A. C., Sevak, R. J., Monterosso, J. R., Hellemann, G., Sugar, C. A., \& London, E. D. (2011). Acute modafinil effects on attention and inhibitory control in methamphetaminedependent humans. Journal Of Studies On Alcohol And Drugs, 72(6), 943-953. doi: $10.15288 /$ jsad.2011.72.943 
340

341

342

343

344

345

346

347

348

349

350

351

352

353

354

355

356

357 358

de Saint Hilaire, Z., Orosco, M., Rouch, C., Blanc, G., Nicolaidis, S. (2001). Variations in extracellular monoamines in the prefrontal cortex and medial hypothalamus after modafinil administration:a microdialysis study in rats. NeuroReport 12: 3533-3537.

Ferraro, L., Antonelli, T., O’Connor, W.T., Tanganelli, S., Rambert, F.A., Fuxe, K. (1997) Modafinil: an antinarcoleptic drug with a different neurochemical profile to damphetamine and dopamine uptake blockers. Biol Psychiatry. 42:1181-3.

Ferraro, L., Fuxe, K., Tanganelli, S., Fernandez, M., Rambert, F.A., Antonelli, T. (2000) Amplification of cortical serotonin release: a further neurochemical action of the vigilance-promoting drug modafinil. Neuropharmacology. 39:1974-83.

Ferraro, L., Fuxe, K., Tanganelli, S., Tomasini, M.C., Rambert, F.A., Antonelli, T. (2002) Differential enhancement of dialysate serotonin levels in distinct brain regions of the awake rat by modafinil: possible relevance for wakefulness and depression. $J$ Neurosci Res. 68:107-12.

Fleisch, V.C., Leighton, P.L., Wang, H., Pillay, L.M., Ritzel, R.G., Bhinder, G., Roy, B., Tierney, K.B., Ali, D.W., Waskiewicz, A.J., Allison, W.T. (2013). Targeted Mutation of the Gene Encoding Prion Protein in Zebrafish Reveals a Conserved Role in Neuron Excitability. Neurobiol Dis. 11-25. doi: 10.1016/j.nbd.2013.03.007

Gerlai, R. (2010) High-throughput behavioral screens: the first step towards finding genes involved in vertebrate brain function using zebrafish. Molecules. 15(4): 2609-22. doi: 10.3390/molecules15042609. 
365 Gerlai, R. (2016) Learning and memory in zebrafish (Danio rerio). Methods Cell Biol. 134: 551-

366

367

368

369

370

371

372

373

374

375 86.

Hamilton, T.J., Myggland, A., Duperreault, E. May, Z., Gallup J., Powell, R.A., Schalomon, M., \& Digweed, S. (2016). Episodic-like memory in zebrafish. Anim Cogn, doi:10.1007/s10071-016-1014-1

Hermant, J. F., Rambert, F. A., Duteil, J. (1991). Awakening properties of modafinil: Effect on nocturnal activity in monkeys (Macacamulatta) after acute and repeated administration. Psychopharmacology; 103(1):28-32.

Holcombe, A., Howorko, A., Powell, R.A., Schalomon, M., Hamilton, T.J. (2013). Reversed Scototaxis during Withdrawal after Daily-Moderate, but Not Weekly-Binge, Administration of Ethanol in Zebrafish. PLoS ONE 8(5): e63319. doi:10.1371/journal.pone.0063319

Holcombe, A., Schalomon, M., Hamilton, T.J. (2014). A Novel Method of Drug Administration to Multiple Zebrafish (Danio rerio) and the Quantification of Withdrawal. J Vis Exp. (93):e51851. doi: 10.3791/51851.

Huang, J., Zhong, Z., Wang, M., Chen, X., Tan, Y., Zhang, S., He, W., He, X., Huang, G., Lu, H.,Wu, P., Che, Y., Yan, Y., Postlethwait, J.H., Chen, W.,Wang, H. (2015). Circadian Modulation of Dopamine Levels and Dopaminergic Neuron Development Contributes to Attention Deficiency and Hyperactive Behavior. J Neurosci. 35(6): 2572-2587. doi: 10.1523/JNEUROSCI.2551-14.2015 
Ingraham, E., Anderson, N.D., Hurd, P.L., \& Hamilton T.J. (2016) Twelve-Day ReinforcementBased Memory Retention in African cichlids (Labidochromis caeruleus). Frontiers in Behavioural Neuroscience. 10. doi:10.3389/fnbeh.2016.00157

Lecendreux, M., Bruni, O., Franco, P., Gringras, P., Konofal, E., Nevsimalova, S., Paiva, T., Partinen, M., Peeters, E., Peraita-Adrados, R., Plazzi, G., \& Poli, F. (2012). Clinical experience suggests that modafinil is an effective and safe treatment for paediatric narcolepsy. Journal Of Sleep Research, 21(4), 481-483. doi:10.1111/j.13652869.2011.00991.x

Loane, C. \& Politis M. (2012) Buspirone: what is it all about? Brain Res. 1461:111-8. doi: 10.1016/j.brainres.2012.04.032.

Madras, B.K., Xie, Z., Lin, Z., Jassen, A., Panas, H., Lynch, L., Johnson, R., Livni, E., Spencer, T.J., Bonab, A.A., Miller, G.M., Fischman, A.J. (2006). Modafinil occupies dopamine and norepinephrine transporters in vivo and modulates the transporters and trace amine activity in vitro. $J$ Pharmacol Exp Ther. 319: 561-569.

Maximino, C., de Brito, T. M., da Silva Batista, A. W., Herculano, A. M., Morato, S., \& Gouveia, A. (2010). Measuring anxiety in zebrafish: a critical review. Behavioural brain research, 214(2), 157-171.

May, Z, Morrill, A, Holcombe, A, Johnston, T, Gallup, J, Fouad, K, Schalomon, M, Hamilton, T.J. (2015) Object recognition memory in zebrafish. Behavioural Brain Research. 296, 199-210.

Mereu, M, Bonci, M., Newman, A.H., Tanda, G. (2013). The neurobiology of modafinil as an enhancer of cognitive performance and a potential treatment for substance use disorders. 
Psychopharmacology (Berl). 229(3): 415-434. doi:10.1007/s00213-013-3232-4.

Minzenberg, M. J., \& Carter, C. S. (2008). Modafinil: A review of neurochemical actions and effects on cognition. Neuropsychopharmacology, 33(7), 1477-1502. doi:10.1038/sj.npp.1301534

Moretz, J. A., Martins, E. P., \& Robinson, B. D. (2007). Behavioral syndromes and the evolution of correlated behaviour in zebrafish. Behavioral Ecology, 18, 556-562. doi:10.1093/beheco/arm011

Murillo-Rodriguez, E., Haro, R., Palomero-Rivero, M., Millan-Aldaco, D., Drucker-Colin R. (2007). Modafinil enhances extracellular levels of dopamine in the nucleus accumbens and increases wakefulness in rats. Behav Brain Res. 176:353-7.

Ou, M., Hamilton, T. J., Eom, J., Lyall, E. M., Gallup, J., Jiang, A., Lee, J., Close, D. A., Yun, S. S., \& Brauner, C. J. (2015). Responses of pink salmon to CO2-induced aquatic acidification. Nature Climate Change, 5(10), 950-955.

Pham, J., Cabrera, S. M., Sanchis-Segura, C., \& Wood, M. A. (2009). Automated scoring of fear-related behavior using EthoVision software. Journal Of Neuroscience Methods, 178(2), 323-326. doi:10.1016/j.jneumeth.2008.12.021

Randall, D. C., Shneerson, J. M., Plaha, K. K., \& File, S. E. (2003). Modafinil affects mood, but not cognitive function, in healthy young volunteers. Human Psychopharmacology: Clinical And Experimental, 18(3), 163-173. doi:10.1002/hup.456

Rasetti, R., Mattay, V. S., Stankevich, B., Skjei, K., Blasi, G., Sambataro, F., \& Weinberger, D. R. (2010). Modulatory effects of modafinil on neural circuits regulating emotion and cognition. Neuropsychopharmacology, 35(10), 2101-2109. doi:10.1038/npp.2010.83 
440 Sackerman, J., Donegan, J. J., Cunningham, C. S., Nguyen, N. N., Lawless, K., Long, A. Gould, G. G. (2010). Zebrafish behaviour in novel environments: Effects of acute exposure to anxiolytic compounds and choice of Danio Rerio line. International Journal of Comparative Psychology, 23(1), 43-61.

Schwartz, J. R., Hirshkowitz, M., Erman, M. K. (2003). Modafinil as adjunct therapy for daytime sleepiness in obstructive sleep apnea: a 12-week, open-label study. 124(6):2192-2199. [PubMed: 14665500])

Sigurgeirsson, B., Porsteinsson, H., Arnardottir, H., Johannesdottir, I. P., \& Karlsson, K. E. (2011). Effects of Modafinil on sleep-wake cycles in larval zebrafish, Zebrafish, 0, 1-8 doi: 10.1089/zeb.2011.0708

Simon, P., Panissaud, J., \& Costentin, J. (1994). The stimulant effect of modafinil on wakefulness is not associated with an increase in anxiety in mice. Psychopharmacology. $114,597-600$.

Spence, R., Gerlach, G., Lawrence, C., Smith, C. (2008) The behaviour and ecology of the zebrafish, Danio rerio. Biol Rev Camb Philos Soc 83: 13-34. doi: 10.1111/j.1469185X.2007.00030.x.

Spiller, H. A., Borys, D., Griffith, J. R., Klein-Schwartz, W., Aleguas, A., Sollee, D. \& Sawyer, T. S. (2009). Toxicity from modafinil ingestion. Clinical Toxicology, 47(2), 153-156.

Stewart, A.M., Kalueff, A.V. (2014). The behavioral effects of acute $\Delta^{9}$-tetrahydrocannabinol and heroin (diacetylmorphine) exposure in adult zebrafish. Brain Res. 1543:109-19. doi: 10.1016/j.brainres.2013.11.002. 
Stewart, A., Gaikwad, S., Kyzar, E., Green, J., Roth, A., \& Kalueff, A. V. (2012). Modeling anxiety using adult zebrafish: a conceptual review. Neuropharmacology, 62(1), 135-143.

Stewart, A.M., Braubach, O., Spitsbergen, J., Gerlai, R., Kalueff, A.V. (2014) Zebrafish models for translational neuroscience research: from tank to bedside. Trends Neurosci. 37(5):264-78. doi: 10.1016/j.tins.2014.02.011.

Tierney, K.B. (2011) Behavioural assessments of neurotoxic effects and neurodegeneration in zebrafish. Biochim Biophys Acta, 1812: 381-389. doi: 10.1016/j.bbadis.2010.10.011.

Tran, S., Facciol, A., Gerlai, R. (2016). Home tank water versus novel water differentially affect alcohol-induced locomotor activity and anxiety related behaviours in zebrafish. Pharmacol Biochem Behav. 144:13-9. doi: 10.1016/j.pbb.2016.02.009.

Tran, S., Nowicki, >., Muraleetharan, A., Chatterjee, D., Gerlai, R. (2016b). Neurochemical factors undelying individual differences in locomotor activity and anxiety-like behavioural responses in zebrafish. Prog Neuropsychopharmacol Biol Psychiatry. 65:2533. doi: 10.1016/j.pnpbp.2015.08.009.

Van Vliet, S.A., Jongsma, M. J., Vanwersch, R. A., Olivier, B., Philippens, I. H. (2006). Behavioral effects of modafinil in marmoset monkeys. Psychopharmacology, 185(4), $433-440$

Wisor, J.P., Nishino, S., Sora, I., Uhl, G.H., Mignot, E., Edgar, D.M. (2001). Dopaminergic role in stimulant-induced wakefulness. $J$ Neurosci. 21: 1787-1794.

Wright, D., Nakamichi, R., Krause, J., Butlin, R.K. (2006) QTL Analysis of Behavioral and Morphological Differentiation Between Wild and Laboratory Zebrafish (Danio rerio). Behav. Genet. 36(2): 271-284. 
487 Young J.W., Kooistra K., Geyer M.A. (2011). Dopamine receptor mediation of the

488 exploratory/hyperactivity effects of modafinil. Neuropsychopharmacology 36: 1358-

489 1396

490

491 


\section{Figure 1 (on next page)}

\section{Experimental set up}

Apparatus used in the novel approach test. (A) The arena used was a plastic circular arena (diameter: $34 \mathrm{~cm}$, wall height: $16 \mathrm{~cm}$ ) placed on a seeding mat to maintain water temperature. (B) The novel object was a multicolour Lego figurine (height: $5 \mathrm{~cm}$, width: 1.5 $\mathrm{cm})$. 

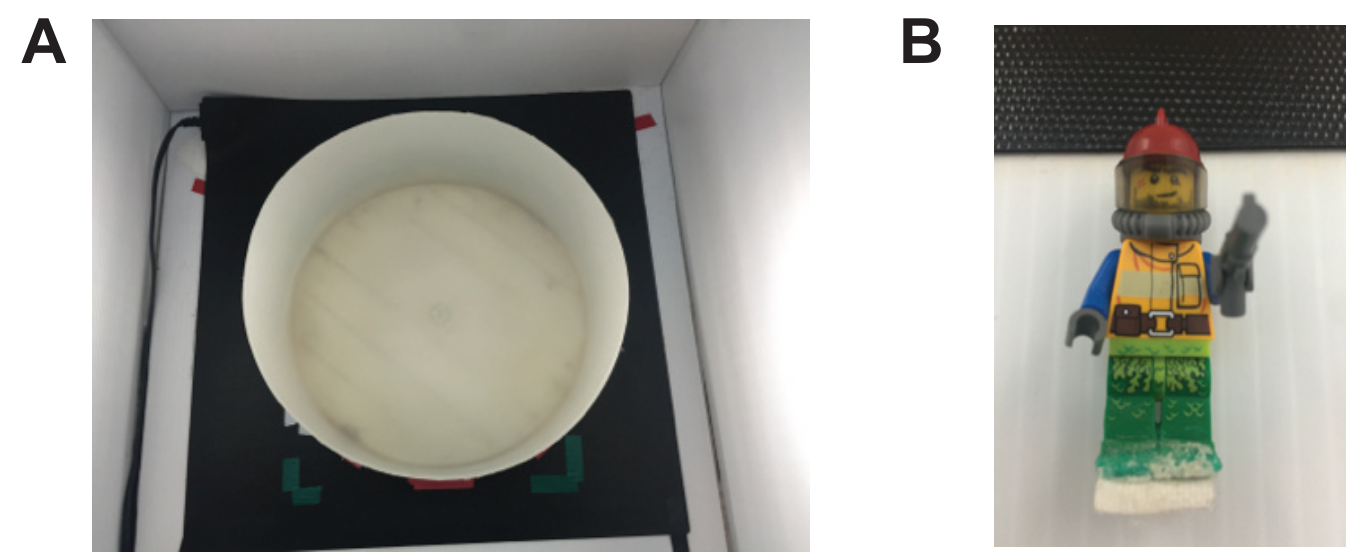


\section{Figure 2 (on next page)}

Zebrafish movement in the novel approach test

Individual fish movement in the novel approach test. (A) Trackplot of an individual fish in the control condition for the 10 minute trial. (B) Trackplot of an individual fish in the $200 \mathrm{mg} / \mathrm{L}$ modafinil condition. (C) Heatmap of the same fish from the control condition in (A). A heatmap is a visualization of the location of the fish over the entire 10 minute trial produced in EthoVision. The colours represent the duration of time the fish spent in each pixel with low wavelengths (ex. Red) indicating high time spent and high wavelengths (ex. Blue) indicating low time spent in each pixel. (D) Heatmap for the same fish from the modafinil $200 \mathrm{mg} / \mathrm{L}$ condition in (B). 


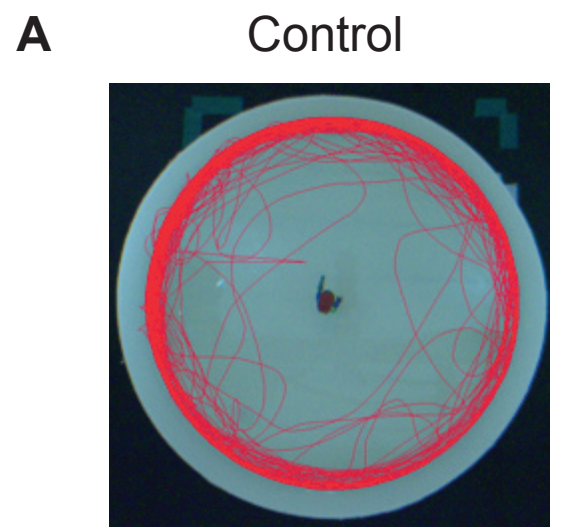

$$
\text { B } \quad 200 \mathrm{mg} / \mathrm{L}
$$

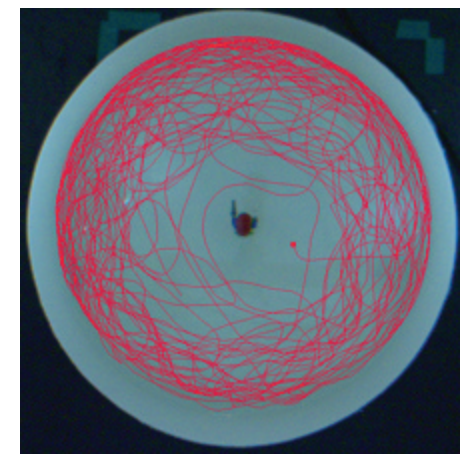

C

Control

D $200 \mathrm{mg} / \mathrm{L}$
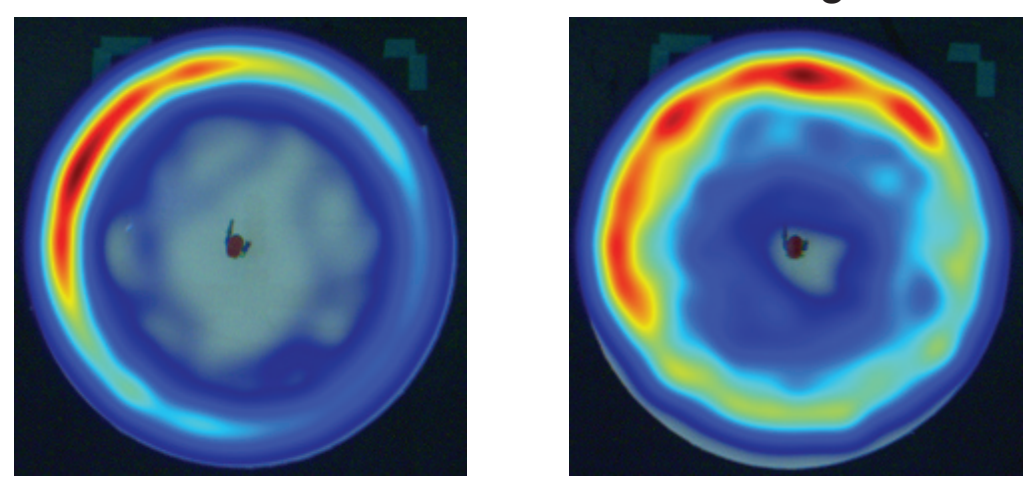


\section{Figure 3 (on next page)}

Zone preference after modafinil dosing

Time in zones of the novel approach test. (A) The time spent in the thigmotaxis zone (near walls) of the arena decreased with modafinil. (B) The time spent in the transition zone (middle zone) of the arena increased with modafinil. (C) The time spent in the center zone (where the object was located) was not significantly different across groups. $* p<.05, * * p<$ 0.01 , difference from control group. 
A

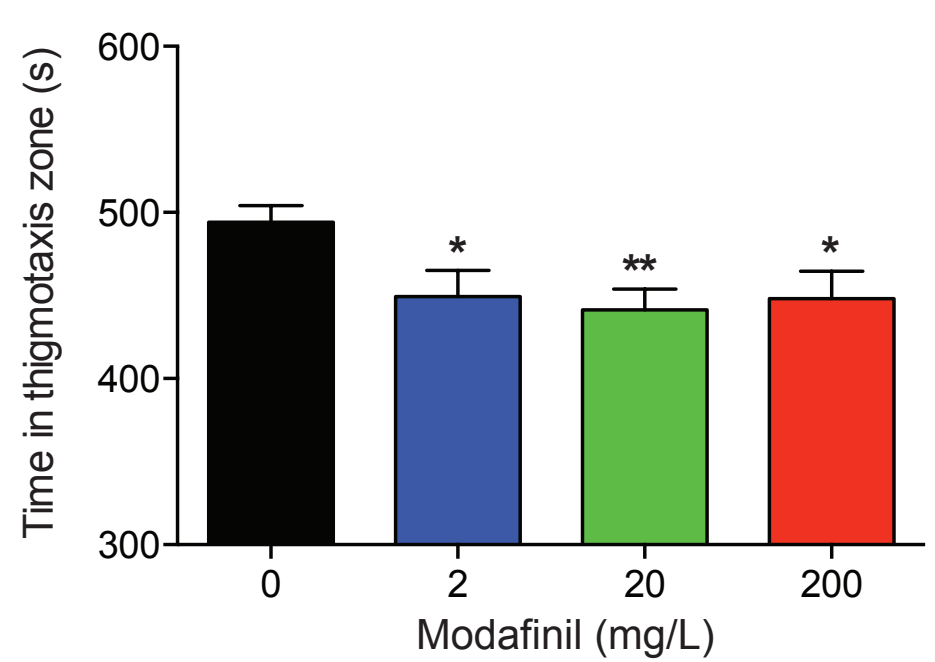

B

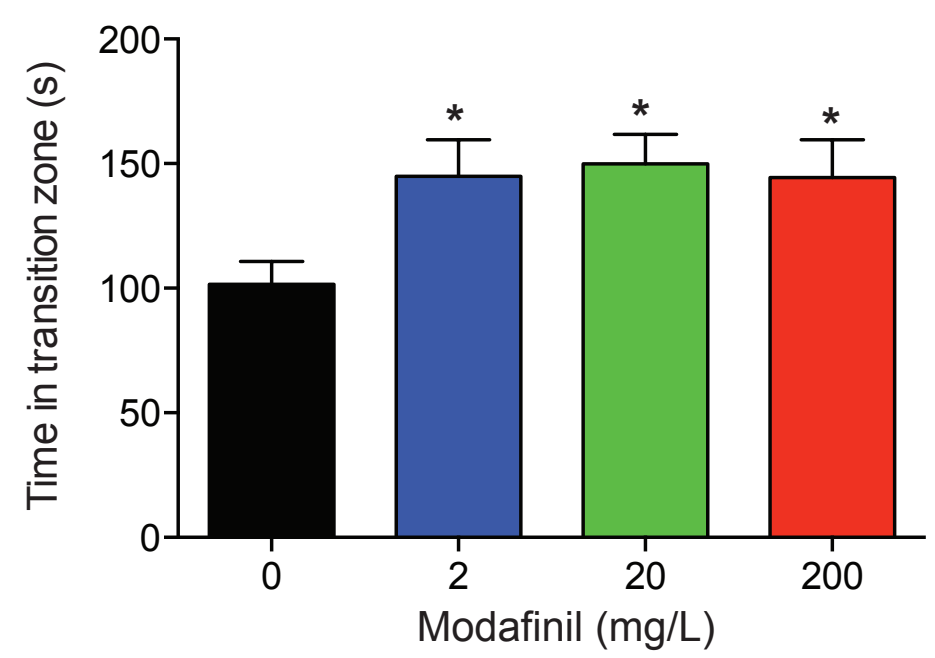

C

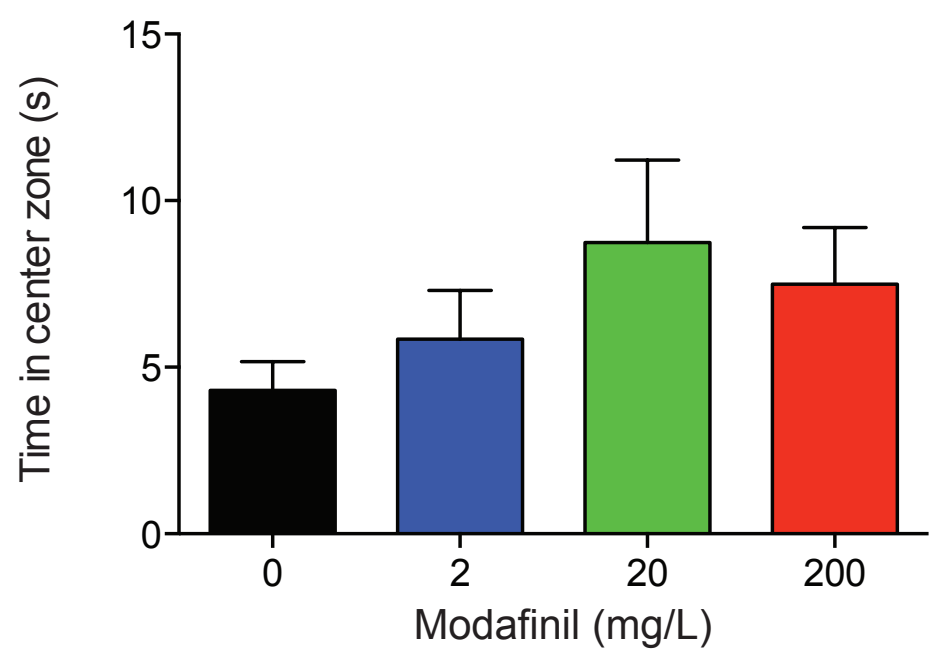




\section{Figure 4 (on next page)}

Locomotion after modafinil dosing

Locomotion variables in the novel approach test. (A) There was no significant difference in

distance moved across all groups. (B) There was no significant difference in meandering across all groups. (C) There was no significant difference in immobility across all groups. 


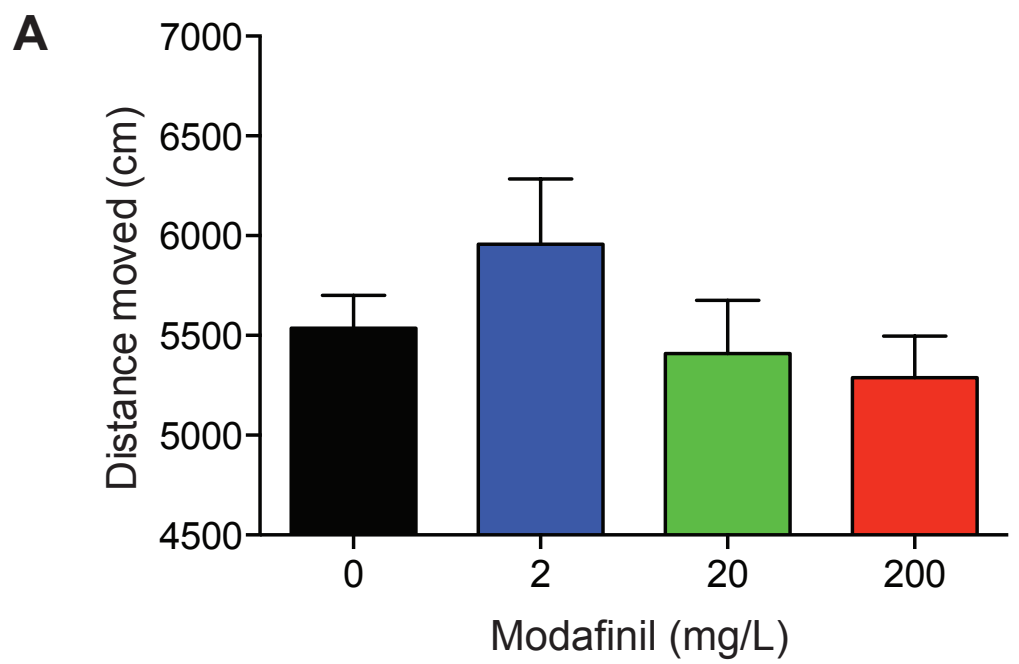

B

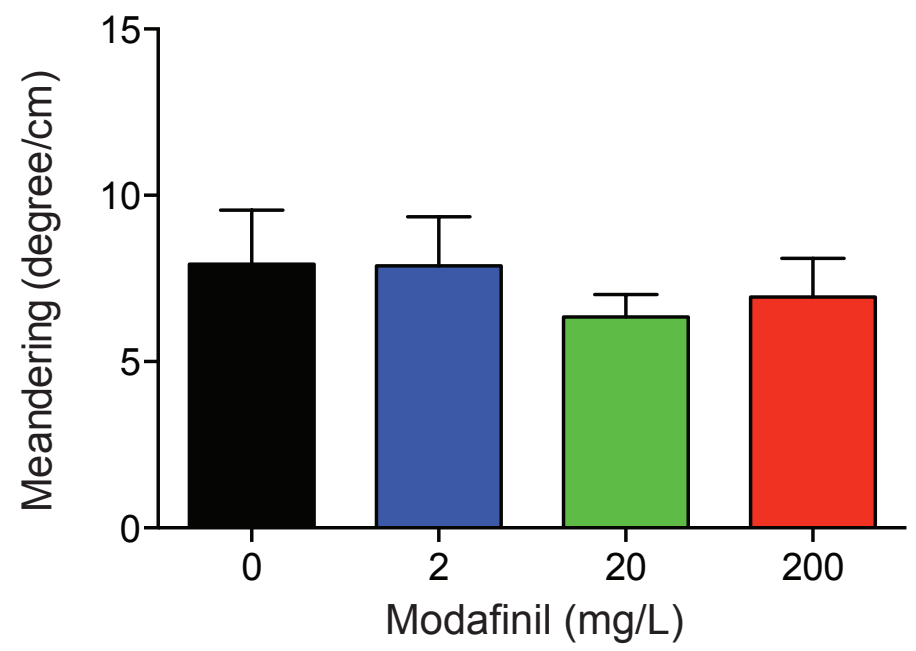

C

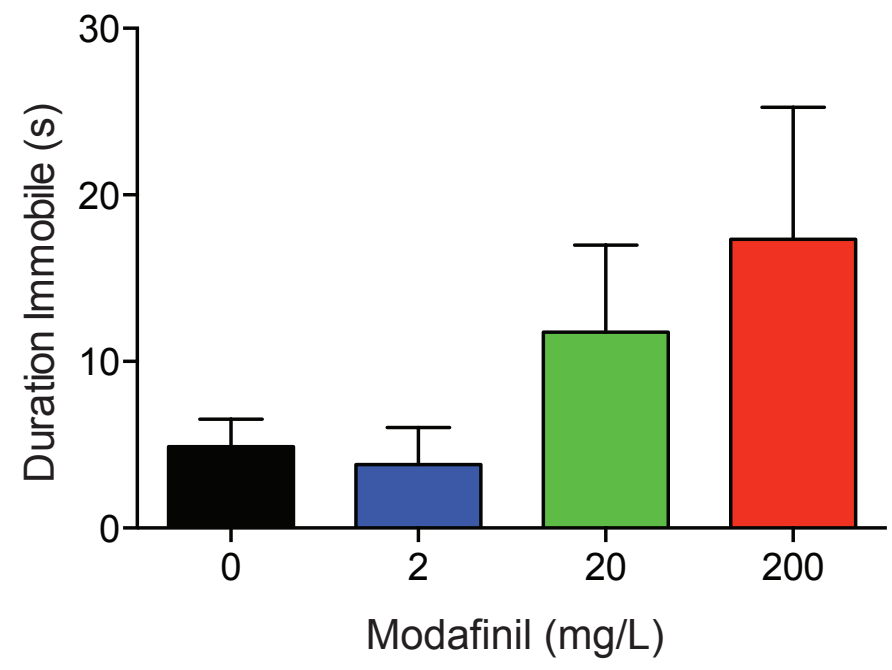




\section{Table $\mathbf{1}$ (on next page)}

Ethanol and the novel approach test

Summary of results from ethanol (1\%) exposed and control fish in the novel approach test. Bold items show significant differences between ethanol and control groups $(\alpha=0.05)$. $P$ values were calculated with an unpaired t-test for parametric data and a Mann-Whitney test for non-parametric data. 
1

2

\begin{tabular}{|l|l|l|l|l|l|l|}
\hline & $\begin{array}{l}\text { Time in } \\
\text { Center }(\mathbf{s})\end{array}$ & $\begin{array}{l}\text { Time in } \\
\text { Transition } \\
(\mathbf{s})\end{array}$ & $\begin{array}{l}\text { Time in } \\
\text { Thigmotaxis } \\
(\mathbf{s})\end{array}$ & $\begin{array}{l}\text { Distance } \\
\text { moved } \\
(\mathbf{c m})\end{array}$ & $\begin{array}{l}\text { Meandering } \\
\text { (degree/cm) }\end{array}$ & $\begin{array}{l}\text { Immobility } \\
(\mathbf{s})\end{array}$ \\
\hline $\begin{array}{l}\text { Control } \\
(\mathbf{n = 1 9 )}\end{array}$ & $2.1 \pm 0.5$ & $102.2 \pm 14.9$ & $478.6 \pm 20.3$ & $3649 \pm 388$ & $5.9 \pm 0.7$ & $58.6 \pm 21.7$ \\
\hline $\begin{array}{l}\text { Ethanol } \\
(\mathbf{n = 2 0 )}\end{array}$ & $1.9 \pm 0.7$ & $199.5 \pm 35.4$ & $387.4 \pm 35.6$ & $3216 \pm 357$ & $6.2 \pm 0.3$ & $126.7 \pm 21.8$ \\
\hline $\begin{array}{l}\text { Control } \\
\text { vs. } \\
\text { Ethanol }\end{array}$ & $\mathrm{P}=0.4167$ & $\mathbf{P = 0 . 0 1 7 6}$ & $\mathbf{P = 0 . 0 3 4 5}$ & $\mathrm{P}=0.4167$ & $\mathrm{P}=0.1257$ & $\mathbf{P}=\mathbf{0 . 0 0 9 0}$ \\
\hline
\end{tabular}

3

4 Table 1

5 Summary of results from ethanol (1\%) exposed and control fish in the novel approach 6 test.

7 Bold items show significant differences between ethanol and control groups $(\alpha=0.05)$.

8 P values were calculated with an unpaired t-test for parametric data and a Mann-

9 Whitney test for non-parametric data.

10 